\title{
Can we predict fire extinction by water mist with FDS?
}

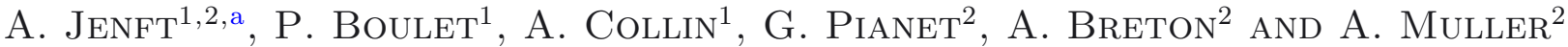 \\ 1 LEMTA, Laboratoire d'Energétique et de Mécanique Théorique et Appliquée, Université de Lorraine, UMR 7563, \\ CNRS, Vandœuvre-lès-Nancy, France \\ 2 CNPP, Centre National de Prévention et de Protection, Vernon, France
}

Received 17 September 2013, Accepted 19 November 2013

\begin{abstract}
Among the primary phenomena observed when studying fire suppression are fuel surface cooling, fire plume cooling and inerting effects. The last two result from water evaporation generating a significant vapor concentration, thus leading to an important heat sink as well as displacement and dilution of both oxygen and fuel vapor. Fire Dynamics Simulator (FDS.v6) is expected to be able to reproduce these effects. Extinguishment criterion focusing on plume cooling and inerting effects is based on a dedicated heat balance, whereas suppression model related to fuel surface cooling evaluates the burning rate decrease according to an exponential law taking into account local water mass reaching the fuel surface per unit area and an empirical constant which penalizes the prediction ability. Therefore, a new model derived from an Arrhenius equation has been implemented, which links the burning rate to the fuel surface temperature. Numerical simulations are conducted and compared with experimental data for all extinguishing mechanisms.
\end{abstract}

Key words: Fire / extinction / water mist

\section{Introduction}

Numerical simulations of fire extinction by water spray has recently emerged among the numerous subjects of research in fire community and has become possible thanks to the improvements made in computer calculation capacities. Moreover, understanding of the physical phenomena involved in fire extinction by water sprays made a lot of progress over the last decades $[4-6]$. This kind of studies is of prime interest in industry since it could be possible to evaluate numerically a sprinkler or water mist system capacities to control or extinguish a typical fire which could occur in warehouses or rooms for exemple and thus for a much less important cost than an experimental test. The main idea is to reproduce the HRR (Heat Release Rate) decrease, and as a consequence the extinction time, with the best accuracy and reliability.

The present study is carried out as a collaborative work between the CNPP European Security Center and LEMTA laboratory, aiming at testing the different extinction models available in FDS by comparing the numerical results to experimental data. Two tests are detailed here, showing different extinguishment mechanisms. In the first one taken from the VINNOVA test series (case 1),

${ }^{a}$ Corresponding author: alexandre.jenft@gmail.com extinction has been attributed to flame cooling and inerting effects as a result of a strong evaporation, while fuel cooling has been identified as the dominating effect in case 2 , selected from a test series carried out by the CNPP and LEMTA. These two types of behaviours are obtained experimentaly by changing pool size, fuel, confinment and water mist characteristics. These observations are confirmed by numerical results, through the analysis of energy balances integrated to FDS.

In FDS 6, extinction criterion by flame cooling and inerting effects is based on a heat balance, while suppression model for fuel cooling is represented by an exponential law linking pyrolysis rate to local water mass on fuel surface per unit area and to an empirical coefficient $a$. As a consequence, this model cannot be used for predictive simulations which is the goal sought by the present work. A new model will be discussed here, derived from an Arrhenius equation in order to model the HRR evolution.

The paper is organized as follows: the experimental tests for both cases will first be described. Then, extinguishment criterion representing flame cooling and inerting effects, as well as the new model implemented to determine extinction due to fuel cooling will be detailed. Finally, numerical results will be compared with experimental data, the emphasis being put on extinction time. 


\section{Experimental tests}

As stated above, the present tests have been selected in order to involve different extinction mechanisms. The first one is consequently a confined fire with high HRR and a limited air renewing (favouring the predominance of vapor action), while the second test involves a moderate HRR and strong air renewing, thus requiring fuel cooling for extinguishment.

\subsection{Case 1}

The VINNOVA test series was conducted in an enclosure measuring $8 \mathrm{~m} \times 12.5 \mathrm{~m} \times 5 \mathrm{~m}$ with a volume of $500 \mathrm{~m}^{3}$ [1]. The fire scenario chosen for this work was a round heptane pool with a diameter of $1.12 \mathrm{~m}$ and an area of $1.0 \mathrm{~m}^{2}$. The pool was filled with $50 \mathrm{l}$ of heptane on a $50 \mathrm{l}$ water bed such that the freeboard was $150 \mathrm{~mm}$. The pool was placed on a scale located centrally on the floor of the test enclosure, and it was obstructed by a $4 \mathrm{~mm}$ thick steel plate measuring $2 \mathrm{~m} \times 2 \mathrm{~m}$ and positioned $1 \mathrm{~m}$ above floor level. For the test modeled below, all ventilation openings in the enclosure were closed, and only allowed to act as pressure relief vents. The pre-burn time was $30 \mathrm{~s}$. At this time, the HRR is about $3 \mathrm{MW}$. The high pressure water mist system for the experiments consisted of four ceiling mounted spray heads. At 70 bar pressure each spray head flowed about $15 \mathrm{l} / \mathrm{min}$. The spray heads were installed with a $5.0 \mathrm{~m}$ spacing in the longitudinal direction and $2.5 \mathrm{~m}$ spacing in the transverse direction of the test enclosure. The experiments were instrumented for gas and surface temperatures, gas concentrations $\left(\mathrm{O}_{2}, \mathrm{CO}_{2}\right.$, $\mathrm{CO}$, relative humidity), radiative heat fluxes, compartment pressure, mass loss rate of the pool, and the water pressure in the suppression system pipe work.

\subsection{Case 2}

This test has been chosen among the test series carried out by the CNPP European Security Center and LEMTA laboratory in an enclosure measuring $3.87 \mathrm{~m} \times 3.83 \mathrm{~m} \times 3.02 \mathrm{~m}$ with a volume of $45 \mathrm{~m}^{3}$. The fire scenario chosen for this work was a round fuel oil pool with a diameter of $0.35 \mathrm{~m}$ and an area of $0.1 \mathrm{~m}^{2}$. The pool was filled with $5 \mathrm{l}$ of fuel oil such that the freeboard was $50 \mathrm{~mm}$. The pool was placed on a scale located centrally on the floor of the test enclosure and was not obstructed. There is a regulated ventilation $10 \mathrm{~cm}$ below the ceiling with a flowrate of $0.43 \mathrm{~m}^{3} \cdot \mathrm{s}^{-1}$. The doors were closed during the tests and one of them had dampers near the bottom to provide an open section toward the outside, thus avoiding an under-ventilated fire. The pre-burn time was $64 \mathrm{~s}$. At this time, the HRR is about $48 \mathrm{~kW}$. The low pressure water mist system for the experiments consisted of four ceiling mounted spray heads. At 10 bar pressure each spray head flowed about $6 \mathrm{l} / \mathrm{min}$. The spray heads were installed with a $0.9 \mathrm{~m}$ spacing in the longitudinal direction and $1.2 \mathrm{~m}$ spacing in the transverse direction of the test enclosure. The experiments were instrumented for gas and surface temperatures, gas concentrations $\left(\mathrm{O}_{2}\right)$, radiative heat fluxes, mass loss rate of the pool, and the water pressure in the suppression system pipe work.

\section{Extinction models}

\subsection{Flame cooling/inerting effects}

To determine extinction by flame cooling and inerting effects, FDS uses the concept of a limiting flame temperature [2], below which combustion is no more supported. In brief, the model examines a grid cell and determines if combustion of the fuel in that cell as a stoichiometric mixture would raise the temperature of that mixture above the limiting flame temperature.

The model has been improved in FDS 6, the sensible enthalpies of the fuel and the local gas mixture without the fuel being now computed at both the gas cell temperature and the limiting flame temperature using temperature dependent look up tables for all the species present. Taken from the paper by Vaari et al. [7], the changes due to stoichiometric combustion in the mass fractions of fuel and the gas mixture without fuel are

$$
\begin{array}{r}
\Delta Y_{\mathrm{F}}=\operatorname{MIN}\left(Y_{\mathrm{F}}, Y_{\mathrm{O}_{2}} / s\right) ; \Delta Y_{g}=s \Delta Y_{\mathrm{F}} \frac{1-Y_{\mathrm{F}}}{Y_{\mathrm{O}_{2}}} ; \\
s=\frac{\nu_{\mathrm{O}_{2}} W_{\mathrm{O}_{2}}}{W_{\mathrm{F}}}
\end{array}
$$

where $Y_{\mathrm{F}}, Y_{\mathrm{O}_{2}}$ and $Y_{g}$ stand for fuel, oxygen and gas mixture without fuel mass fractions, $\nu$ is the yield and $W$ is the molecular weight for the corresponding species.

The enthalpy differences are

$$
\Delta h_{\mathrm{F}}=h_{\mathrm{F}}\left(T_{L}\right)-h_{\mathrm{F}}\left(T_{g}\right) ; \Delta h_{g}=h_{g}\left(T_{L}\right)-h_{g}\left(T_{g}\right)
$$

with

$$
h_{g}=\sum_{\alpha} Y_{\alpha} h_{\alpha} ; \quad h_{\alpha}(T)=\int_{T_{0}}^{T} c_{p, \alpha}\left(T^{\prime}\right) \mathrm{d} T^{\prime}
$$

where $h$ is the enthalpy, $T$ is the temperature and $c_{p}$ the specific heat of the corresponding species $\alpha . T_{L}$ is the limiting flame temperature.

Combustion is not allowed and local extinction occurs if the enthalpy difference between the two temperatures is greater than the heat of combustion for that mixture (i.e. not enough energy is released to raise the gas temperature to the limiting flame temperature):

$$
\Delta Y_{\mathrm{F}} \Delta h_{\mathrm{f}}+\Delta Y_{g} \Delta h_{g}>\Delta Y_{\mathrm{F}} \Delta H_{C}
$$

with $\Delta H_{C}$ the heat of combustion. 


\subsection{Fuel cooling: current model}

FDS suppression model assumes an exponential reduction of the mass loss (and hence of the HRR) through the relationship

$$
\dot{m}_{f}^{\prime \prime}(t)=\dot{m}_{f, 0}^{\prime \prime} \mathrm{e}^{-\int k(t) \mathrm{d} t}
$$

where $\dot{m}_{f, 0}^{\prime \prime}$ is the mass loss per unit area on the pool when the water mist is injected and $k(t)$ is related to the liquid mass per unit area that reaches the fuel surface $\left(m_{p / f}^{\prime \prime}\right)$ as follows

$$
k(t)=a m_{p / f}^{\prime \prime}(t)
$$

with $a$ an empirical constant. Presence of an empirical term in pyrolysis rate calculation prevents any use of this model for predictive simulations which is the goal sought by the present work, hence our new model proposal.

\subsection{Fuel cooling: new model}

Our new model proposal, implemented to represent extinction due to fuel cooling, is derived from the Arrhenius equation. The Arrhenius equation is a simple relationship for the temperature dependence of reaction rates. It is frequently used in the combustion domain to determine burning rate versus fuel surface temperature and therefore seems to be suitable for the present purpose. It is written as follows

$$
\dot{m}_{f}^{\prime \prime}(t)=A \exp \left(-\frac{B}{T_{f}(t)}\right)
$$

where $A$ and $B$ are empirical coefficients which can be easily determined measuring HRR evolution with fuel surface temperature.

This law is traditionnaly used without water mist. However, nothing prevents its use in this case. In the present form, equation (7) cannot determine extinction alone. Indeed, a fire is extinguished when its surface temperature is lowered below the fire point, $92{ }^{\circ} \mathrm{C}$ for example in case 2 detailed here considering the fuel used. The drawback is that equation (7) would predict a burning rate different from zero, whatever the surface temperature, even below the fire point. Equation (7) also represents HRR growth poorly for near ignition fuel temperatures. A modification has been added to these ends and the law is now written

$$
\dot{m}_{f}^{\prime \prime}(t)=A \sqrt{T_{f}(t)-T_{\text {ign }}} \exp \left(-\frac{B}{T_{f}(t)}\right) .
$$

\section{Numerical simulations}

Two models can be used in FDS to simulate a fire by determining either a prescribed burning rate through time or pyrolysis parameters. The first one is the most commonly used in fire safety engineering which motivated

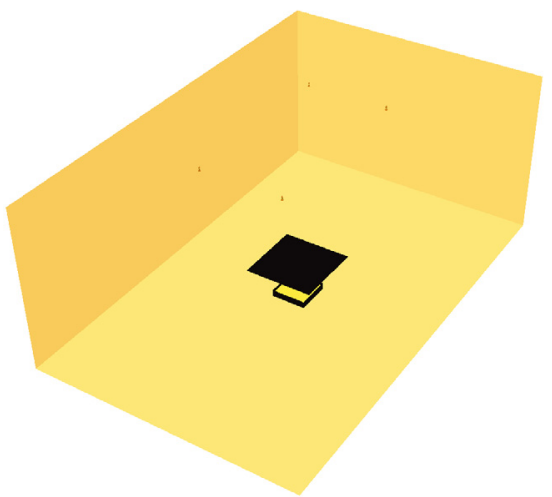

Fig. 1. FDS model of case 1.

our choice to evaluate its performance in the present work for both cases. However, we will describe the differences we could obtain with both models, especially for case 1. We will focus here on determination of extinguishment time compared with experimental results.

\subsection{Case 1}

FDS model of case 1 can be observed in Figure 1. The spatial resolution of the model was $10 \mathrm{~cm}$ and the mean volume diameter of the water droplets was $83 \mu \mathrm{m}$. The pool fire was extinguished in the experiment $175 \mathrm{~s}$ after mist activation (or $205 \mathrm{~s}$ after ignition). Limiting flame temperature was $1500{ }^{\circ} \mathrm{C}$ in our simulation. By using a detailed pyrolysis model, we reach extinction $177 \mathrm{~s}$ after mist activation and HRR decreases slowly to this point (Fig. 3). This representation fits experimental results very well, when compared with [7] and thus becomes our reference result. Prescribed burning rate has been used in an easier way, the only combustion parameters entered being chemical composition and heat of combustion. We assumed here the user would only know HRR (i.e. pyrolysis rate) evolution without water mist. As can be seen in Figure 3, HRR growth before mist activation fits the results obtained with pyrolysis model very well but FDS does not reproduce the same HRR first drop $20 \mathrm{~s}$ after spraying, neither does it reproduce slow decrease until extinction when using precribed burning rate model. However, it can determine fire extinguishment, with a less acceptable accuracy on extinction time though (31\% instead of $1 \%$ ).

It should be noted that use of pyrolysis model is possible here because heptane is a well-known and simple fuel. With more complex fuels, using this model can become much harder and it is often prefered to use a prescribed HRR. Moreover, a particular attention must be paid to water spray modeling when simulating fire exinghuisment due to inerting effects and flame cooling.

\subsection{Case 2}

Case 2 is presented in Figure 2. The spatial resolution of the grid was $5 \mathrm{~cm}$ and the mean volume diameter of the 


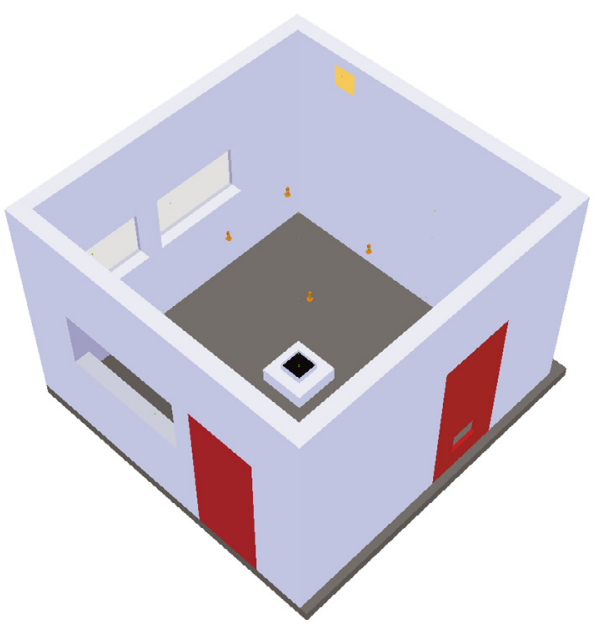

Fig. 2. FDS model of case 2 .

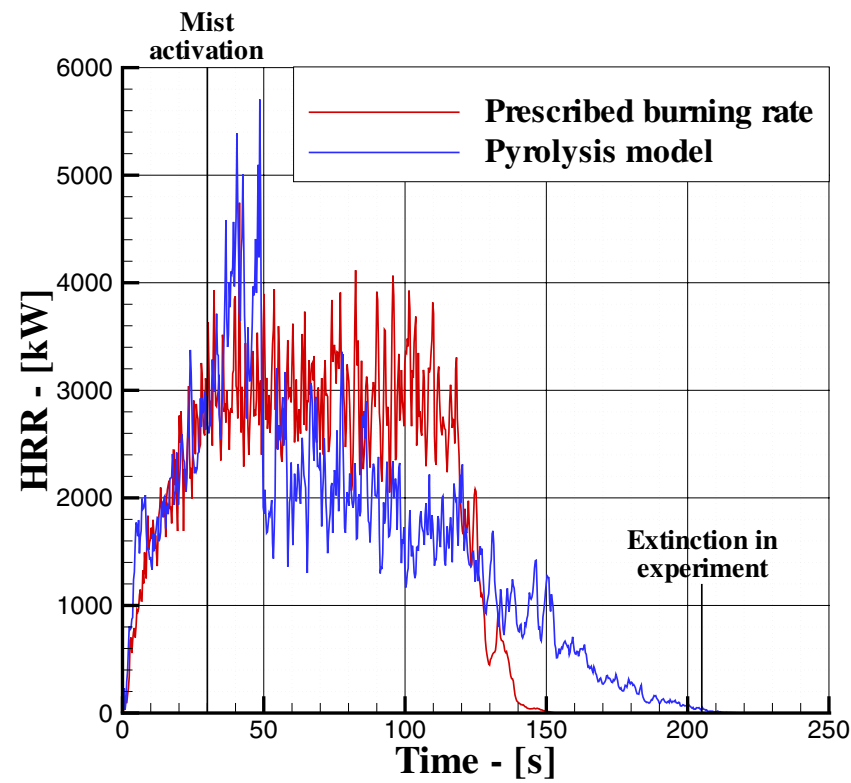

Fig. 3. HRR versus time in case 1 .

water droplets was $112 \mu \mathrm{m}$. The pool fire was extinguished in the experiment $65 \mathrm{~s}$ after mist activation.

In this situation (extinction due to fuel cooling), prescribed HRR is used and HRR growth has to be well reproduced since only the fuel temperature will determine the burning rate during spraying. Fire extinction was reached only $37 \mathrm{~s}$ after mist activation here when equation 8 is used as the extinction model. As explained earlier, if the first model (Eq. (7)) is used, extinction cannot be reached (Fig. 4). When analysing the fuel surface temperature (Fig. 5), the fuel surface cooling effect is obvious as the temperature falls below the fire point, which was not possible in case 1 since heptane was used and its fire point is $-4{ }^{\circ} \mathrm{C}$. This confirms that both effects can be reproduced. However, there is a discrepancy with experimental results considering the extinction time. It can be attributed to the questionable prediction of the fuel

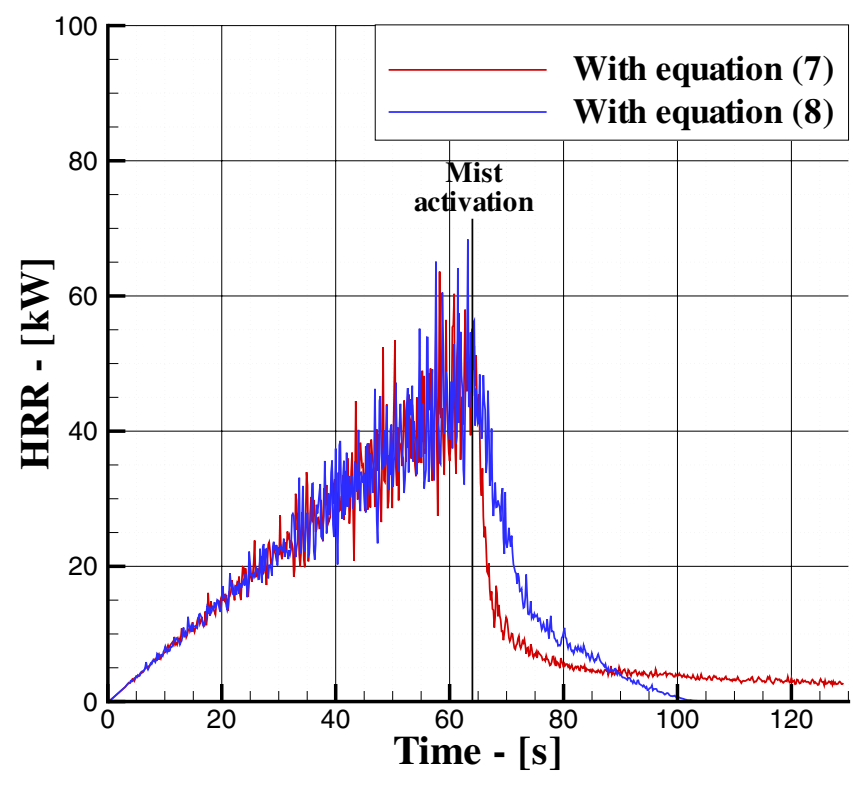

Fig. 4. HRR versus time in case 2 .

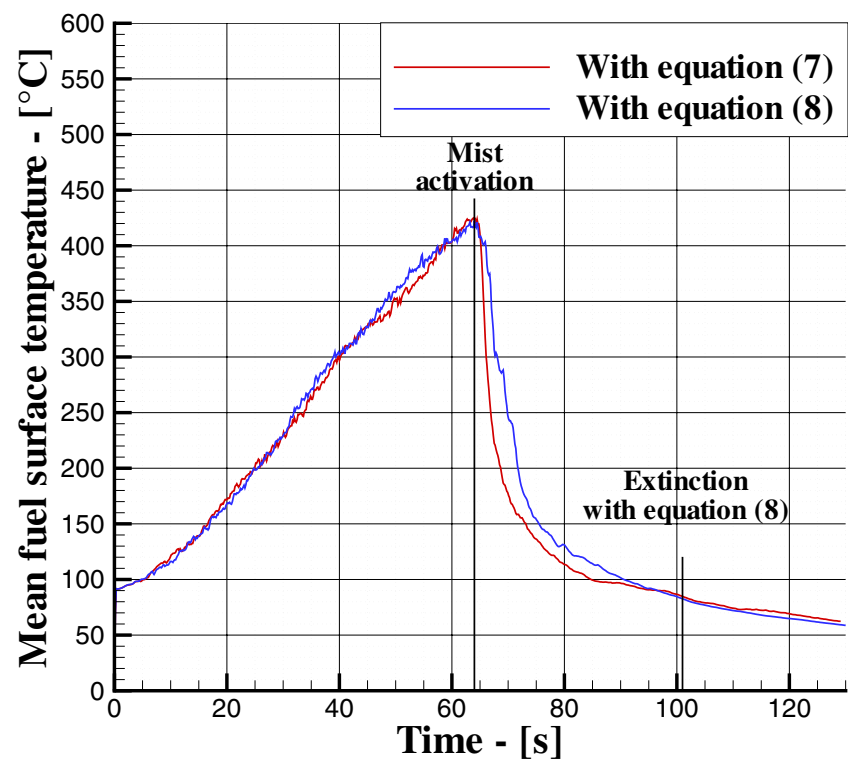

Fig. 5. Fuel temperature versus time in case 2.

temperature. Among the identified problems in the heat transfer model, the followings will require a special care :

- FDS overpredicts water evaporation, especially for small droplets, possibly resulting in overprediction of droplet size decrease during their course, but also in a higher cooling of the fuel surface when droplets reach it and evaporate on it [3] ;

- Heat transfer between fuel surface and droplets is calculated as solid / liquid film exchanges. When a droplet reaches the fuel surface, it crushes to become a rectangular block and slides on it. FDS will not account for the fact that water can be heavier than a liquid hydrocarbon fuel: water will not sink into or below the fuel layer, and the resulting effects are not 
captured. Moreover, fuel surface / droplet exchanges are modeled as follows:

$$
\dot{Q}_{\text {cond }}=A h_{S}\left(T_{S}-T_{l}\right)
$$

where $A$ is the area of the fraction of the liquid film exposed to the wall, $T_{S}$ and $T_{l}$ stand for fuel and droplet temperature respectively and $h_{S}$ is an equivalent heat transfer coefficient between the liquid and the fuel surface. Its value is $300 \mathrm{~W} \cdot \mathrm{m}^{-2} \cdot \mathrm{K}^{-1}$ but no information can be found about this value in the literature and the justification of this value can be questionable. Therefore, improvement of the fuel surface/droplet exchange is our current main work.

\section{Conclusions}

Numerical simulations have been carried out with FDS to determine its capacities to determine fire extinguishment. Extinction time obtained numerically was compared to experimental data in 2 cases representing distinct extinguishing mechanisms: flame cooling and inerting effects in case 1, fuel surface cooling in case 2 .

FDS model for flame cooling and inerting effects reproduces experimental results very well when using pyrolysis model. Results obviously become worse if the fuel is not well-known. However, FDS is still able to determine if there is extinction or not in this case, even when the only information given is the nominal HRR. This model has been validated at reduced scale and now needs more experimental results for validation at full scale.

A new model has been implemented to reproduce fire extinction due to fuel surface cooling. It links pyrolysis rate to fuel surface temperature in the same way it is proposed by Arrhenius equation. Qualitatively, the extinction ability is predicted. Results still show significative discrepancies with experimental results for extinction time. However, improvements can be made regarding evaporation and fuel surface/water droplet heat transfer models.

\section{References}

[1] M. Arvidson, T. Hertzberg, The VINNOVA water mist research project: a description of the $500 \mathrm{~m} 3$ machinery space tests, SP Report 19 (2003)

[2] C.L. Beyler, Flammability Limits of Premixed and Diffusion Flames, In SFPE Handbook of Fire Protection Engineering (ed. National Fire Protection Association), 2002, pp. $2.172-2.187$

[3] E. Blanchard, Modelisation de l'interaction entre un brouillard d'eau et un feu en tunnel. PhD Thesis, University Henri Poincaré, Nancy, France, 2011

[4] G. Grant, J. Brenton, D. Drysdale, Fire suppression by water sprays, Fire Safety J. 26 (2000) 79-130

[5] Z. Liu, A.K. Kim, Review of water mist fire suppression systems - fundamental studies. J. Fire Protection Eng. 10 (2000) 32-50

[6] J.R. Mawhinney, G.G. Back III, Water Mist Fire suppression Systems. In SFPE Handbook of Fire Protection Engineering (ed. National Fire Protection Association) (2002) pp. 4.311-4.337

[7] J. Vaari, S. Hostikka, T. Sikanen, A. Paajanen, Numerical simulations on the performance of water-based fire suppression systems. VTT Technology 54 (2012) 